\title{
INTENTIONAL EMOTIONS AND KNOWLEDGE ABOUT GOD
}

\author{
EVA-MARIA DÜRINGER
}

University of Tübingen

\begin{abstract}
Some recent theories of emotion propose that emotions are perceptions of value laden situations and thus provide us with epistemic access to values. In this paper I take up Mark Wynn's application of this theory to religious experience and try to argue that his McDowell-inspired account of intentional emotions leads to limitations for the justificatory force of religious experiences and to difficult questions about the metaphysical status of the object of religious experiences: if emotions and religious experiences are largely similar, then, just as emotions, religious experiences cannot justify beliefs about the existence of objects, but merely beliefs about certain qualities they might have. Also, if emotions and religious experiences are largely similar, then, just as the objects of emotions, the object of religious experience turns out to be essentially mind-dependent.
\end{abstract}

For a long time emotions seemed to have a rather bad reputation, at least where the acquisition of knowledge was concerned. It seemed to be a truth universally acknowledged that if you wanted to understand a certain subject matter properly, you should look at it when you are calm and level headed, and not when you are under the influence of an emotional disturbance. In the last thirty or forty years this negative picture of emotions has changed to an extent. Whilst it seems still true that, when you want to acquire knowledge in the natural sciences, for example, you are more likely to succeed when you are calm and collected than when you are in the middle of an anger episode, emotions are no longer thought to be without any epistemic merit at all. On the contrary, when you want to acquire knowledge about whether a certain act is cruel or kind, whether a certain person is amiable or abominable, and whether a certain piece of art is beautiful or repulsive, emotions are not 
only helpful but indispensible. How can that be? One thought is to say that emotions are like perceptions. Just as perceptions represent objects as having certain primary or secondary qualities, emotions represent objects as having certain evaluative properties. And just as perceptions that represent objects as having a certain quality justify beliefs about objects as having certain qualities, emotions that represent objects as having certain evaluative qualities justify beliefs about objects as having certain evaluative qualities, too.

Mark Wynn has recently taken this theory of emotions and applied it to religious experiences. If I understand him correctly, his idea is that religious experiences can be understood as being on a par with emotions. Just as emotions are not mere blind sensations, but intentional mental states that tell us something about the world around us, religious experiences are not blind sensations of a mysterious character, but rather intentional mental states that tell us something about God. In this paper I want to try to retrace Wynn's thoughts and examine if, and if yes, how, an application of current positions in the philosophy of emotions to the phenomena of religious experiences can indeed be fruitful.

\section{WYNN'S IDEA}

In this section I want to present Wynn's position as developed in the first chapter of his book Religious Experience and Religious Understanding (2005). I should say right away that Wynn's claims are much more modest than the positions I will go on to look into and criticise. At the very outset Wynn writes that

I am not trying to provide a comprehensive treatment of the epistemic significance of theistic experience, but just to consider how certain standard objections to such experience may be seen in a new light given a reconceived account of the nature of emotions. (2005: 3)

In the following I will look at Wynn's description and refutation of said objections, before I will leave Wynn's footsteps to see in the next couple of sections what such a new treatment of the epistemic significance of theistic experience may look like and which problems it might encounter.

Perhaps, before discussing objections to theistic experiences and how they may be presented in a new light, one should ask what such experiences actually look like. This is a difficult question, as we are talking here about an experience that not all of us have had and that 
we thus cannot take to be generally familiar. I take it that what Wynn has in mind is an emotional encounter with God, an 'affectively toned' experience of God's presence (e.g., Wynn 2005: 5, 28). One of the few examples of religious experiences that Wynn gives is a description of John Henry Newman's account of an experience of God in hearing the voice of one's conscience (Wynn 2005: 18). Interestingly, Wynn claims along with Newman that in hearing the voice of conscience, we have an experience of God, not of something else that is pointing to God, even though this experience is mediated. How are we to understand this? I think the idea may be this: in experiencing a pang of guilt, say, we experience God directly, even though God's presence is mediated by the pang of guilt. Thus, even though our experience of God's presence, or his voice, is clothed within emotions, it is by the mediation of these emotions that God himself can be felt. The natural next question is why one should believe that some emotions are indeed mediators of God's presence, rather than just mere subjective sensations that come and go without mediating anything. This, in fact, is the objection that Wynn mentions in the quote at the beginning of this section. Even though it may be true that when we are in religious environments like churches, or when we pray, or when we think about what God's reaction to our actions may be, we experience a whole range of emotions, it is not clear why we should think that these emotions have a mediating function. They may as well be blind sensations, mere feelings that overcome us, just as spontaneous chills and aches. I will call this the blindness objection.

It is at this point that Wynn turns to recent discussions in the philosophy of emotions, or, more precisely, the philosophy of values. Within the philosophy of values we also find a version of the blindness objection. Value experiences, one might think, are not genuine experiences of something that exists in the world, but mere blind emotional sensations. When I experience a certain action as cruel, then my mixture of disgust and anger is not an experience of a genuine value property of cruelty that the act somehow possesses, but rather a blind sensation, which I in turn project onto the value-free reality in which the act takes place. This position, which takes it that what happens in value experience is not the recognition of some real value property, but the projection of a sensation onto a value-free reality, is called Projectivism. Put negatively, Projectivism is a version of the blindness objection: value experiences are not intentional mental states that can correctly represent the world as being a certain way, but mere sensations that we project onto 
a value-free world. Wynn's strategy to counter the blindness objection against religious experience is to look for a refutation of the blindness objection against value experience, which he finds in the work of John McDowell. The following is a summary of McDowell's argument against Projectivism as reconstructed by Wynn (2005: 3-6):

(1) Projectivism presumes that all value experiences can be disentangled into value-free external elicitors and purely subjective affective sensations.

(2) Such a disentanglement is not always possible.

(3) Hence, Projectivism is false.

The first premise looks uncontroversial, at least if we add that the disentanglement must be possible in principle, even if it is difficult in fact. The second premise requires an explanation. Why is it that value experiences cannot always, at least in principle, be disentangled into value-free elicitors and subjective experiences? One argument that McDowell puts forward and that Wynn discusses is that if such a disentanglement was always possible, then it would also be possible for someone who does not share our value experiences at all, who perhaps lacks emotional dispositions altogether, to master the use of our value concepts and apply them competently. This would be odd. If we imagine a Mr. Spock type character, that is a creature without any affectivity at all, to come and live amongst us, master our evaluative language and call an instance of wanton violence against an animal cruel, then even though his application of the concept 'cruel' would be right in a respect, we probably still would not credit him with having a proper understanding of what 'cruel' means. If he does not, and cannot, feel angry, disgusted, and pity when he sees an animal being beaten, then he cannot really see the cruelty of the act. Even if he knew the whole range of non-evaluative properties to which we reacted with this mixture of anger, disgust and pity, and he knew that we reacted that way and in turn projected our reactions onto the non-evaluative properties in question, we would still not credit him with an understanding of the meaning of cruelty. If this intuition is along the right lines, then we must conclude that our emotions are not mere blind reactions that we project back onto a value-free world, but that they are states that enable us to see something that is there, something that a person without emotions cannot see. Otherwise Mr. Spock, knowing all there is to know about the extensions of value experiences and the workings of human affectivity, but without 
experiencing emotions himself, should have a proper understanding of values. He does not, hence Projectivism is wrong.

The intuition pushed here is similar to the one Peter Goldie means to trigger with his thought experiment of ice-cold Irene. In an analogy to Frank Jackson's Mary, the colour scientist in a black and white world, Goldie wants us to imagine icy-cool ice scientist Irene, a woman who knows all there is to know about ice, who also knows that people often have fear reactions towards icy surfaces, but who has never felt fear herself in her life. One day, she slips on an icy pond and suddenly begins to fear ice herself. As Goldie puts it,

Before, she knew that the ice was dangerous, for she knew that it merited fear, but, because she now is able to think in a new way of fear, she now understands in a new way what it is for the ice to be dangerous. (Goldie 2002: 245)

Similarly, we may imagine Mr. Spock as suddenly feeling anger, disgust and pity when seeing a dog being mistreated. Now, we want to say, he knows more than he did before. He suddenly is able to grasp what it means that the act is cruel, the value of cruelty is properly presented to him - something that was not the case from the perspective of all his theoretical knowledge before.

Is the intuition that is pushed by McDowell's thought experiment of a non-emotional user of value concepts and Goldie's icy-cool Irene one that is strong enough to support premise two in the argument against Projectivism? In order to assess this, I think it is useful to introduce yet another analogy. There are certain emotional experiences and associated values that we can talk about competently, without ever having had the experience ourselves. Think of a person whose partner has been diagnosed with a terminal illness. We can try to imagine the horrible prospect of losing someone dear to us, how hard it must be to try to make his or her remaining time as cheerful as possible without letting ourselves be overcome by sadness and grief, but we will not really know the true meaning of such an event unless we are in this situation ourselves. Nevertheless, we use the concepts referring to such unexperienced horrors accurately. Undoubtedly we learn something and possibly begin using these concepts properly when we face the described situation ourselves. The question, however, is, whether this really means that a disentanglement between experience and elicitor is impossible, or whether it means something else. I think it means something else. 
When you suddenly enter a situation that, up until then, you just observed from the third person perspective, then you learn what it is like to have a particular experience - be this the experience of seeing something red, feeling fear, or the horror of a prospective loss. Within a Projectivist picture, you are suddenly the one doing the projecting, rather than just the one observing others projecting whatever it is that they are experiencing. Your experience does not reveal something that you could not see before. But you know now that which is being projected. Before, you could point to the usual elicitors and the characteristic behaviours, observable from the third person perspective, that would make up a particular value. You could say, this is a situation in which someone knows that someone who is close to him will die soon, he is very shaken by this, this must be a most horrible situation - but you did not know what it meant. Now that you are in this situation, in which the observable characteristics are much the same, you know what it means - because you are the one who is shaken and who projects all his sadness onto the situation at hand. The brute intuition that the person who has a particular value experience knows more than the person who is just able to apply the value concept accurately without ever having had the relevant value experience is thus easily accommodated by the Projectivist.

McDowell's argument is, however, not so easily refuted. The thought behind premise two is not merely that, were a complete disentanglement possible, then people like Mr. Spock would be potential competent users of value concepts, but that, were a complete disentanglement possible, then we should expect more or less clearly defined groups of nonevaluative properties that make up the appropriate elicitors of particular value experience. For example, we should expect a clearly defined group of natural properties, such as causing a creature harm in order to produce pleasure in the bystanders and taking pleasure in watching such acts, as the appropriate elicitors of emotional reactions which, projected onto such acts and dispositions, make up the concept 'cruel'. If it was not possible to produce such a clearly defined group of natural properties as the appropriate elicitors of an emotional reaction, then the application of a value concept would become random. I could call anything that causes me to have a particular emotional reaction cruel and would not, could not, ever be wrong. And such a complete subjectivism and relativism simply does not accurately describe our practise of using value concepts. We do argue about whether things are cruel, whether they are 
kind or whether they are funny rather than accepting just any odd value ascription as making sense.

How does this relate to McDowell's argument? The main thought behind premise two, it seems, is that a disentanglement of a value experience into value-free elicitors and subjective responses is impossible because there is not always a clearly defined group of value-free elicitors for each value experience. The example McDowell relies on is that of funniness. A lot of things seem to be rightly called funny, even though they do not seem to have a relevant class of non-evaluative properties in common. If we do not assume that they share the property of 'being funny', then our concept application would be random and unlike ordinary concept application. Thus, we should take it that that which the concept 'funny' refers to is the property of being funny, rather than just any odd natural property that happens to make us laugh.

Is this a more plausible support for premise two? One worry is that it might be too dependent on the example of funniness. If we take concepts like 'cruel' and 'kind', then the elicitor groups appear much less diverse. 'Cruel', it could be said, refers to the natural properties of causing a creature harm for no good reason; and 'kind', it could be said, refers to the natural properties of helping, soothing and supporting others without expecting anything in return. In other words, perhaps disentanglement is possible for a large number of value experiences, and where it is not possible, as in the case of finding something funny, the value concept does indeed not refer to anything in particular, but consists in a mere subjective reaction to whatever it happens to be that causes it. Another worry is that, even though it might be impossible to find a clearly defined group of non-evaluative properties that appropriately elicit value responses, this does not mean that such value responses cannot be inappropriate. The Projectivist, I take it, can claim that what makes a value response appropriate is whether or not it is appropriately embedded in, or consistent with, our other value responses. I can thus be criticised for applying the concept 'funny' to a joke that is mainly about racist behaviour. If I object strongly to racist behaviour, then treating an instance of it as harmless would be inappropriate.

I do not want to pursue arguments against McDowell's and Wynn's attacks against Projectivism any further, but rather at this point conclude the following: based on his portrayal of McDowell's arguments against Projectivism in chapter one of Emotional Experience and Religious Understanding, Wynn wants to claim that religious emotional experiences 
do not have to be conceived of as blind sensations, but can be viewed as intentional mental states that reveal something about the world to us. I hope to have shed some doubt over McDowell's arguments against Projectivism, but I do not think that they are the main worry about Wynn's attempt to use McDowell's arguments in order to show how religious experiences can be experiences of God. In the following I want to try to show that, even if we assume that McDowell is right with his criticism of Projectivism, his view of what values and value experiences are seems, when applied to religious experiences, more damaging than constructive.

\section{MCDOWELL'S THEORY OF VALUE}

Wynn wants to make plausible the idea that religious emotional experiences are possibly experiences of God. All he shows, however, is that Projectivism as a rival account of value experiences, that is as blind sensations, is not very good. I tried to show in the last section that perhaps Projectivism is not as bad a theory as McDowell and Wynn make it look, but let us leave that aside. What does a more positive picture look like? If not in a Projectivist way, how exactly are we to understand value experiences? I want to draw a brief sketch of how McDowell does understand them and then show why this understanding might not be as conducive to Wynn's goal as he seems to think it is.

McDowell (1998) develops his theory of values in response to J.L. Mackie's (1977) arguments against the objectivity of values. His main aim is to show that Mackie works with a wrong notion of objectivity. With a right understanding of objectivity, so McDowell argues, values can be thought of as objective after all. It is his development of the right sort of objectivity, and here mainly his claim that values should be understood as on a par with secondary, and not primary, qualities, that has led to the picture of emotions as intentional mental states that have the function to provide access to the evaluative, which Wynn wants to make use of. I think, therefore, that a good understanding of McDowell's value theory should be the starting point for assessing Wynn's thought that religious emotions may be an epistemic access to God.

McDowell agrees with Mackie that we do not think of values as being there in the world in the same way as we think of atoms and molecules as being there in the world, or as we think of densities, shapes and sizes 
as being there in the world - that is, as existing independently from the way we think and feel about them. Mackie argues that if values did exist in the world mind-independently, they would be 'utterly different from everything else in the universe' (Mackie 1977: 38), for they would at the same time be there, whether or not humans are or ever have been around, and demanding a particular type of action from us, as soon as we happen to perceive them. It is this combination of independent existence and intrinsic demandingness that Mackie finds odd. McDowell finds it odd, too, but criticizes Mackie for having set the standards of objectivity for values unfairly high. This odd combination would only be required if values were supposed to be objective in the same way as primary qualities are. But values are not supposed to be objective in this way, but rather, or so McDowell argues, in the same way as secondary qualities are. In contrast to primary qualities, secondary qualities are not mind-independent. We do not think of them as playing an explanatory role in a scientific picture of the world, a picture that makes no reference to how we think and feel about the world. Instead, we acknowledge that qualities such as being of a certain colour, having a particular smell, tasting, sounding or feeling a certain way are all mind-dependent. Take the quality of being sour as an example. To be sour an object does not only need to have a certain chemical make-up, it also needs to taste sour. Even though an object could be sour and not ever be tasted by anyone, it is still true that what makes it sour is that it would taste sour to someone like us under suitable circumstances.

How does an analogy to secondary qualities help to save the objectivity of values? After all, as we have just seen, secondary qualities are essentially mind-dependent, that is, essentially consist of dispositions to cause certain mental states. Does this not play into Mackie's hands and show that values are subjective? It does not, and the reason is that secondary qualities are not simply projected by us onto the world in a way that every projection is permissible. Secondary quality ascriptions can be true or false, which means that secondary qualities must be more than mere figments of the brain: in order to have a false secondary quality ascription, it must be possible for a perception of a secondary quality to be inaccurate. Some perceptions thus are mere figments of the brain, whereas others get something right. McDowell puts his point this way:

two notions that we must insist on keeping separate: first, the possible veridicality of experience (the objectivity of its object, in the second 
of the two senses I distinguished), in respect of which primary and secondary qualities are on all fours; and, second, the not essentially phenomenal character of some properties that experiences represent objects as having (their objectivity in the first sense), which marks off the primary perceptible qualities from the secondary ones. (McDowell 1998: 139)

The two senses of objectivity that McDowell distinguishes here are these: experiences, such as perceptions, are experiences of objects. If these experiences are such that they are either accurate or mistaken, that is, if experiences are assessable in these terms, then the object of the experience cannot be wholly determined by the experience itself. This is the second sense of objective that McDowell talks about. Both primary and secondary qualities are objective in this sense, because experiences of both of them are assessable in terms of truth and falsehood, or accuracy and inaccuracy. The first sense of objectivity McDowell talks about refers to the way in which we have to think of qualities: primary qualities we think of as not essentially phenomenal, which means as not having as a necessary ingredient a property that is in some way mind-dependent. When we experience an object as having a certain shape, then in order to think of the object as having this shape, we do not need to think of how the object appears to us. The opposite is true, however, of secondary qualities. When we experience an object as having a certain colour, then in order to think of the object as having this colour, we must think of how the object appears to us - namely as looking red, blue, yellow or whatever the colour in question is. To sum up: both secondary and primary qualities are objective in the sense that experiences of them can be accurate or inaccurate, whereas primary qualities are also objective in the sense that they are not essentially phenomenal, and secondary qualities are subjective in the sense that they are essentially phenomenal.

Values, McDowell goes on to argue, are analogous to secondary qualities. They also are objective in that experiences of them can be accurate or inaccurate, and they are also subjective in that they are essentially phenomenal. Take the property of being admirable as an example. When we admire something, our admiration can be accurate or it can be mistaken, depending on whether the object is question really is admirable or not. In this sense, the evaluative property of being admirable is objective. Whether an object really is admirable or not is determined by whether or not it is, or would be, admired by 
suitable people under suitable circumstances. In this sense the property of being admirable is subjective - it is essentially phenomenal in that it has a disposition to cause a certain mental state, that is, admiration, as an essential ingredient.

In order to reconnect all this with Wynn's idea that certain emotional religious experiences may be experiences of God, let us see what it means for the nature of emotions. McDowell himself does not seem to be too interested in this question, but on the back of his theory of values other philosophers have developed a picture of emotions as analogous to perceptions of secondary qualities (e.g. Deonna 2006, Döring 2007). It is easy to see why McDowell's theory of values lends itself nicely to such a theory of emotions. McDowell gives us a way in which to understand the concept and metaphysics of values by referring to the concept and metaphysics of secondary qualities. If we want to understand the epistemology of values, it seems natural to look at the epistemology of secondary qualities and see if we can find useful comparisons. There we see that perceptions of secondary qualities, such as seeing a red apple, hearing a loud bang, smelling a flowery perfume, or tasting a sweet cake, are our epistemic access to them. In other words, not only do perceptions of secondary qualities play a crucial role in the metaphysical make up of secondary qualities, they are also the way in which we get to know about them. For an apple to be red is for it to look red under suitable circumstances to a suitable observer, and knowing that an apple is red takes our perceiving it to be red. The same thing may now be said about values: not only do emotions about evaluative properties play a crucial role in the metaphysical make-up of evaluative properties, but knowing that an act is admirable takes our admiration for the act.

We have come then from telling a metaphysical story about values to telling an epistemological story about values; a story that involves that emotions serve as epistemic access to a mind-dependent world of values.

\section{A PROBLEM FOR WYNN'S IDEA}

The thought that Wynn wants to make plausible is that religious emotions are not, at least not in all cases, blind sensations, but intentional mental states that can serve as epistemic vehicles. He wants to do this by showing that ordinary emotions are epistemic vehicles to ordinary values, which he does by referring to McDowell's work. In the first section I introduced 
McDowell's arguments against Projectivism, which are the ones that Wynn actually uses. They end, however, in a negative picture: we might, if we accept them, believe that emotions are not blind sensations, but we are in the dark as to what they actually are. In order to provide a positive picture, I introduced in section two McDowell's value theory, which lends itself to a perceptual theory of emotions. I take it, but cannot be certain, that this is something close to what Wynn has in mind for a positive picture of emotions.

In this section I want to show that, if a perceptual theory of emotions on the back of McDowell's value theory is what Wynn has in mind, then he runs into difficulties. In order to do this, I will first try to spell out the analogy between ordinary emotions and religious emotions on this picture, and then show that it is far from clear how we are to understand the intentional object of a religious emotion.

Ordinary emotions, on the perceptual theory, are intentional mental states that ascribe evaluative properties to objects. Fear, for example, is about a dangerous animal; anger is about an offensive remark; and gratitude is about a helpful or kind act. The intentional content has two main ingredients: a particular object, which is the object in the world at which the emotion is directed (e.g. the animal, the remark, or the act) and a formal object, which is the evaluative property that is ascribed to the particular object (e.g. the property of being dangerous, offensive or helpful). Perceptual theories of emotions take it that emotions begin with a non-emotional cognitive state, such as a perception of an object, or a belief about a state of affairs. I see a tiger, for example, or believe that this remark was intended to hurt me, or believe that this act was performed with the intention to get me where I want to get. This so called cognitive base of an emotion (see e.g. Deonna and Teroni 2012: 5 ) is then followed by the actual emotion: we ascribe to the particular object given in the cognitive base an evaluative property. The evaluative property, or formal object of an emotion, also serves as a standard of appropriateness for emotions. Fear is only appropriate if the object in question is really dangerous; anger is only appropriate if the remark in question is really offensive; and gratitude is only appropriate if the action in question is really helpful.

With this theory of ordinary emotions in place, we can ask with Wynn what religious emotions may look like. Religious gratitude and consolation are presumably experiences of God as helping us in difficult situations. Religious fear is presumably an experience of God as 
potentially punishing our wrong-doings. Religious hope is presumably an experience of God as potentially giving us a good life after death. What is striking is that in all these emotional experiences, God figures as the particular object of an emotion. This is a problem for Wynn, because particular objects are not given to us by the emotion itself, but by the cognitive bases of emotions - perceptions, beliefs, imaginations, hallucinations, illusions and so on. If this is correct, and I indeed do not know of any emotion theory that has it that the particular object is given by the emotion, then this means that knowledge of God cannot be attained via emotions, but must be attained by some other cognitive means. Put differently: perceptual theories of emotions take it that emotions are means to gaining knowledge about values, but not means to gaining knowledge about the existence of the objects who possess these values.

Even though standard perceptual theories do not hold that emotions are means to gaining knowledge about the existence of particular objects, could one not perhaps stretch the theory so as to make room for this? Take the example of your waking up in the middle of the night in a state of terrifying fear. At first you don't know what it is that you are so afraid of, but then you get up and begin to search your house for intruders. You eventually find out that there indeed had been someone in the house, but that he has already left, having taken various valuables with him. Could we in this case not say that your fear was a means to gain knowledge about an object that was threatening you? Could we not say that it was a hint that set you on the trail of the burglar? Wynn might have something like this in mind with his example of John Henry Newman's description of an experience of a bad conscience, which I described in section one. Wynn's interpretation of this example is that, when we experience such a pang of guilt, we experience God directly, although mediated through this pang of guilt. It is not clear how exactly God is meant to enter into this experience, as the particular objects of guilt are our own actions, and the formal object is the evaluative property of wrongness: when I feel guilty about having lied to someone, I feel guilty about my wrong action. So where does God come in? Perhaps Wynn takes it that what we actually experience, namely guilt about a wrong-doing of ours, has a flipside: deference to someone. Even though God might not immediately enter into the content of our emotional experience, it is him at whom our deference is directed. 
Given that instances of emotional experiences in which the particular object is at first unknown, that is, emotional experiences that do not seem to be preceded by a cognitive base, do occur, are we not justified in concluding that emotions can be ways of getting to know about the existence of objects? I do not think so.Take the burglar example again: you could say that it was your fear that made you aware of the burglar, but the more plausible explanation of the example would be that you unconsciously perceived a noise that triggered your fear response. Your means of knowing that there's a burglar in your house is not your sudden fear, but your unconsciously experienced perception of a noise, confirmed by a search of the house that made it clear that someone had been in and taken things away. Perhaps it would still be correct to say that it was your fear that in some way hinted to you that something was wrong, but if there were no means independent of emotions to find out whether or not a supposed object of an emotion exists, then we would not rely on our emotion as evidence for the existence of that object. Instead, we would say that we were afraid, but that our fear turned out to be inappropriate, because no dangerous object could be made out.

Or could perhaps another reference to the analogy between perceptions of secondary qualities and emotions as perceptions of evaluative properties give fresh support to the idea that emotions can be evidence for the existence of primary objects? After all, perceptions of the secondary qualities of objects have the power to convince us that the object that possesses them really exists. When we think that there might be a cat in the house, and then smell a cat smell and hear a miaow somewhere, then these perceptions of secondary qualities add to the evidence that the cat really exists. Might not a sudden fear of cats do the same? I do not think that many of us would answer this question affirmatively. If someone says 'I knew that the cat was there because I smelt it', this does make sense. The speaker's belief seems indeed prima facie justified by his olfactory perception. But if someone says 'I knew that the cat was there because I was suddenly afraid of it', then we would question the speaker's justification. Why is that? Possibly the main difference between the two cases has to do with the function of the mental states in question. Perceptions of all kinds have the function to inform us of what is there, whereas emotions of all kinds do not have that function. Instead, it is their function, or so the perceptual theorist generally has it, to inform us of the evaluative properties of objects (see e.g. Prinz 2004: 66). So when we are experiencing an emotion, we are 
not in the business of finding out what there is, but whether that which is there is in some way good for us or not. Thus, when we fear God, or feel deference or gratitude towards him, then we do not thereby become convinced that he exists. If these feelings hit you out of the blue, and you are someone who does not already believe in God's existence, then you will not by having these emotions become convinced that God exists. Either you must acknowledge that you have believed in God's existence all along, without having been aware of it, or you must conclude that your emotions are inappropriate. But to begin to believe that God exists on the basis of sudden fear of him would be unjustified.

Let us assume, then, that emotions provide in the first place information about evaluative properties, but not about the existence of the objects to whom the properties belong. What this means for Wynn is that the idea that emotions provide us with knowledge about the existence of God seems hard to maintain. At least if religious emotions worked in a way that is similar to ordinary emotions, then a perception of or a belief about God should serve as the cognitive base to which emotions like gratitude or fear are reactions. It would then, however, be this perception or this belief that served as the main provider of knowledge about God's existence, rather than the reactive emotion. Does this mean that Wynn's idea should be given up? Not necessarily. Wynn sometimes expresses himself in a way that lends itself to an interpretation of religious emotions that is not on a par with ordinary emotions as conceived of by perceptual theorists. Consider the following two quotes: 'perhaps theistic experience can be understood (in some cases anyway) as a kind of affectively toned sensitivity to values that "make up" Gods reality?' (Wynn 2005: 5) and 'we should think of the source of religious experience as a set of value-indexed qualities, and not some set of properties which can be adequately characterized in quantitative (or in general, in non-normative) terms' (Wynn 2005: 21). Wynn seems to endorse the fact here that if emotions get us in touch with anything, then it will be with values. Nevertheless, he seems to deny that in order to ascribe values, we must have a cognitive base that provides us with the object to whom the values are ascribed. Instead, he seems to think it possible that the object can be thought of as 'made up of values', as a 'set of value-indexed qualities'. What could this mean?

First of all we should note that, if Wynn is right, then religious emotions seem to be different from ordinary emotions. Ordinary emotions ascribe value properties to objects previously given in 
a cognitive base, whereas religious emotions in some way sense values, which are in turn not ascribed as properties to some object, but which make up an object. To put the same point differently: ordinary emotions are reactions to objects that we believe exist, or that we see, imagine, or hallucinate. The properties that emotions ascribe to the objects are not properties that are essential to the object. A tiger is still a tiger, even if it is not dangerous. Ordinary emotions thus do not inform us about essential properties, but non-essential aspects of objects that might be important to us. In contrast to this, religious emotions would, on this new reading, not be reactions to believed, perceived, imagined or hallucinated objects, but rather first encounters with God's essential properties. God would, on this reading, be an entity composed of various values such as helpfulness, awe-inspiringness, kindness, and so on. If we read 'make up' as necessary, even though possibly not sufficient, conditions for God's existence, then God would be these values. A weaker reading, such as for a example a reading that sees God as a being that possesses these properties, but that sees them as neither sufficient nor necessary for God's existence, might be more plausible, but would have to give up the idea that emotions are an epistemic access to God's existence. For if the evaluative properties are not essential, then all we have encountered is a set of evaluative properties, and we are back to the dealing with cases of emotions without particular objects. As I tried to show earlier, such emotions are generally seen as inappropriate, rather than as epistemic hints to hitherto unknown objects.

Does it make sense to say that the evaluative properties we encounter in religious emotions are essential properties of God? I think it might make sense, but I also think that we would have to take consequences on board that I am not sure Wynn and like-minded people would like to take on board. If we go back to McDowell's analogy between values and secondary qualities, we will see that he describes secondary qualities, and hence by analogy also values, as essentially phenomenal, even though possibly veridical. What it means for a quality to be essentially phenomenal is for it to consist essentially in a disposition to cause certain mental states. Colours are like that, as well as smells, noises, and sounds. It makes sense to say that values are like that too. For something to be admirable, it has to be such as to evoke admiration in the right circumstances, for something to be pitiful, it has to be such as to evoke pity in the right circumstances, and for something to be kind, it has to be such as to evoke gratitude in the right circumstances. Let's now go 
one step further with the analogy: for something to be God, it has to be such as to evoke awe, fear, gratitude, etc., in the right circumstances. This follows directly from saying that God has values as essential properties and applying McDowell's theory of values. But what we are saying here is nothing else than that God is essentially mind-dependent, just as colours, smells, and the property of being admirable. It takes reference to us, or creatures like us, for these properties to come into existence. It is not the case that it merely takes sensory apparatuses like ours, or emotional sensibilities like ours, to get these properties in view. That is, the phenomenality of secondary qualities is not a mere epistemological matter, so that we can say that these properties are there independently of us, and we can think of them as being there independently of us, but it takes certain sensibilities to become aware of them. No, the thesis is metaphysical: without reference to these certain sensibilities these properties would not be there. And to say this about God's essential properties is to say that in order to give a full account of the kind of being that God is, we need to make reference to these sensibilities. God is essentially mind-dependent.

Maybe it is possible to maintain such a position. If we say that response-dependent qualities such as awe-inspiringness, kindness and fearsomeness are necessary, but not sufficient essential qualities of God, then perhaps we could still believe that God also possesses responseindependent qualities such as being omniscient and omnipotent. Such beliefs about God's response-independent properties, however, could not be justified by reference to religious emotions. The bigger problem though seems to be this: is it possible to maintain a belief about God as the creator of the universe, including creatures like us, if we must think of God as a being that, without a reference to sensibilities like ours, would not exist? Can he have created our sensibilities, if it takes a reference to our sensibilities for him to exist?

To come to a conclusion, let me summarise the following points as the main ones I would like to make regarding Wynn's thought on religious emotions as possible epistemic accesses to God: first, Wynn's reliance on McDowell's arguments against Projectivism is possibly too strong and results in a merely negative picture of religious experiences - they are not necessary blind experiences, but if they are not blind, what exactly are they? I tried to fill in this picture by drawing further on McDowell's work, in particular his analogy between values and secondary qualities. The general idea that emerged was that emotions are perception-like 
states, and that their content can be fruitfully compared to the content of perceptions of secondary qualities. I think there are two main problems when one tries, as Wynn does, to interpret religious experiences on the lines of ordinary emotions as seen by perceptual theorists. One is that ordinary emotions do not justify beliefs about the existence of their particular objects. Thus, we cannot claim by comparison that religious experiences can justify beliefs about the existence of God. Second, if we take the evaluative properties that an emotion ascribes to an object as essential properties of that object - as Wynn seems to suggest, but as perceptual theorists would deny - we end up with a picture of God as, at least partly, essentially mind-dependent.

Acknowledgment. This paper was originally presented in Tübingen, Germany, in October 2013, at a conference for the Analytic Theology Project, generously funded by the John Templeton Foundation. I would like to thank the audience, as well as Anja Berninger, Rob Dennis, Sabine Döring, Anika Lutz, Gundula Reinshagen, and Ruth Tietjen for helpful comments.

\section{BIBLIOGRAPHY}

Deonna, Julien A. 2006. 'Emotion, Perception and Perspective', Dialectica, Vol. 60: $29-46$

Deonna, Julien A. and Fabrice Teroni. 2012. The Emotions: A Philosophical Introduction (Abingdon: Routledge)

Döring, Sabine. 2007. 'Seeing What to Do: Affective Perception and Rational Motivation', Dialectica, Vol. 61: 363-94

Goldie, Peter. 2002. 'Emotions, Feelings and Intentionality', Phenomenology and the Cognitive Sciences, Vol. 1: 235-54

Mackie, J.L. 1977. Ethics: Inventing Right and Wrong (London: Penguin)

McDowell, John. 1998. Mind, Value and Reality (Cambridge, MA: Harvard University Press)

Prinz, Jesse. 2004. Gut Reactions: A Perceptual Theory of Emotion (Oxford and New York: Oxford University Press)

Wynn, Mark. 2005. Religious Experience and Religious Understanding (Cambridge: Cambridge University Press) 